\title{
Improved High Rate Capabilities of Composite Cathodes for Lithium Ion Batteries
}

\author{
Sang-Young Lee ${ }^{\dagger}$ and Yeon Uk Jeong ${ }^{\dagger+*}$ \\ 'Department of Chemical Engineering, Kangwon National University, Chuncheon, Kangwon-do 200-701, Korea \\ ${ }^{\dagger \dagger}$ School of Materials Science and Engineering, Kyungpook National University, Daegu 702-701, Korea
}

(Received November 10, 2008 : Accepted November 18, 2008)

\begin{abstract}
In an attempt to achieve high rate capability of cell, a new composite cathode was prepared by mixing host compounds with MWCNTs and Super P carbon. Because MWCNTs generally have bundle-type morphologies, it is not easy to get completely separated form. Successful dispersion of divided small bundles between the host particles keeps electrochemical contacts among the particles and plays a significant role in the buffer action as a volume-change absorber. Relative amounts and distributions of the additives are important for design of the electrode for high power application of lithium ion batteries.
\end{abstract}

Keywords : Composite cathode, MWCNTs, High rate capability.

\section{Introduction}

One of the advantages of secondary lithium batteries is high energy density as they offer higher potentials than those of other rechargeable systems. ${ }^{1)}$ Layered host materials for electrode of lithium ion batteries have been investigated as they have reversible lithium migrations. $\mathrm{LiCOO}_{2}$ cathodes are commercially available in the market. Recently, $\mathrm{LiMO}_{2}(\mathrm{M}=\mathrm{Ni}, \mathrm{Co}, \mathrm{Mn}, \mathrm{Al}$, etc.) materials were developed for economic and environmental concerns. The amounts of lithium intercalation of these materials mainly depend on the nickel contents in the compounds. Compared to $\mathrm{LiCoO}_{2}$, demerits of these materials are low densities, electrical conductivities, and rate capabilities. For high power applications, it is important to improve electronic conductivities as well as flexibilities of the electrodes. Nano-sized carbon black has been used as conducting agent for cathode of lithium ion batteries.

Since the discovery of carbon nanotubes (CNTs), many applications were attempted and still going on. ${ }^{2}$ ) In order to use as additive in other materials, many investigations on the dispersion of CNTs were done. ${ }^{3-7)}$ Applications of CNTs as additives in lithium ion batteries were reported. ${ }^{8-11)}$

*E-mail: jeong@knu.ac.kr
In this research, the effects of multi-walled carbon nanotubes (MWCNTs) on electronic, and electrochemical properties of lithium ion batteries were investigated. Composite cathodes with MWCNTs exhibited improved discharge capacities and cycle lives at high C-rates.

\section{Experimental}

MWCNTs were synthesized by catalytic chemical vapor deposition process of Iljin Nanotech in Korea. The length and diameters of MWCNTs were 10 20 $\mu \mathrm{m}$ and $10 \sim 15 \mathrm{~nm}$, respectively. $\mathrm{LiNi}_{0.3} \mathrm{Co}_{0.3} \mathrm{Mn}_{0.3} \mathrm{Al}_{0.1} \mathrm{O}_{2}$ sample was prepared by co-precipitation reaction followed by heat treatment. MWCNTs and Super P carbon were dispersed in N-methyl-2-pyrrolidone (NMP) by ultrasonic treatment for 5 minutes. The slurries were prepared by mixing appropriate amounts of materials in binder solution in homogenizer at $5000 \mathrm{rpm}$ for $10 \mathrm{~min}$ utes. The weight ratios of solids and polyviny-lidene fluoride (PVDF) binder were $90: 10$. The composite slurries were coated on aluminum current collectors followed by drying in an oven for 30 minutes at $120^{\circ} \mathrm{C}$. The typical values of electrode thickness after roll pressing were of $90 \sim 100 \mu \mathrm{m}$.

For the battery tests, coin cells were assembled in an argon-filled glove box. A lithium metal foil was used as 
the counter electrode and polypropylene film with the thickness of $18 \mu \mathrm{m}$ was used for separator. A $1 \mathrm{M}$ $\mathrm{LiPF}_{6}$ in a mixture of ethylene carbonate (EC), ethyl methyl carbonate (EMC) and diethyl carbonate (DEC) was used as electrolytes. The cycle range was $4.3 \sim 3.0 \mathrm{~V}$ vs. $\mathrm{Li} / \mathrm{Li}^{+}$and $1 \mathrm{C}$ rate was $150 \mathrm{mAh} / \mathrm{g}$. The charge tests were carried out with a constant current of $0.1 \mathrm{C}$ for the first charge and $0.2 \mathrm{C}$ for the next charges. For discharge tests, various constant current of $0.1 \sim 5.0 \mathrm{C}$ were applied one after another with a cell to evaluate the rate capabilities. Van der Pauw method was used to evaluate electrical conductivities of composite electrodes. Samples were prepared by coating the slurry on polyester film, then pressed and cut into a square piece of $2 \times 2 \mathrm{~cm}$. Four corners of a piece were contacted on the measuring
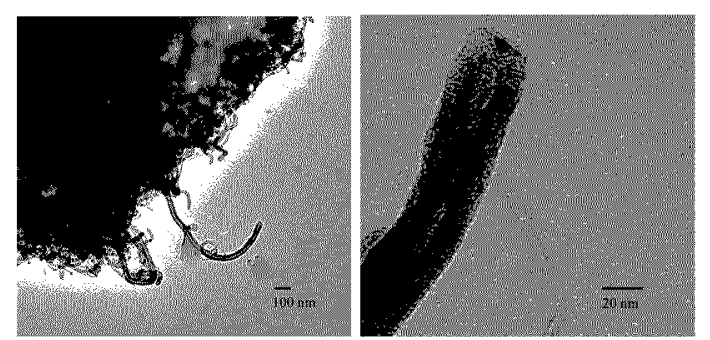

Fig. 1. T.E.M. pictures of MWCNTs bundles and a tube.

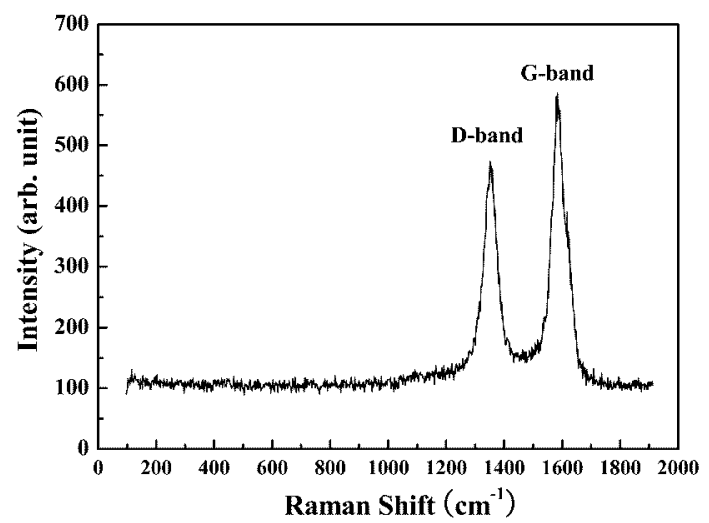

Fig. 2. Raman spectrum of MWCNTs with an excitation wavelength of $514.5 \mathrm{~nm}$. device using silver paint and the resistivity was measured at room temperature.

\section{Results and Discussion}

MWCNTs were synthesized by catalytic CVD process of Iljin Nanotech in Korea. As shown in Fig. 1, MWCNTs have a bundle-type shape and an open tip was observed in the magnified T.E.M. picture of a tube. Fig. 2 shows Raman spectrum of MWCNTs with an excitation wavelength of $514.5 \mathrm{~nm}$. G-band and D-band was observed at $1580 \mathrm{~cm}^{-1}$ and $1353 \mathrm{~cm}^{-1}$, respectively. The intensity ratio $\left(I_{G} / I_{D}\right)$ was 1.31 , and it is known that D-band is due to the defects on the tube wall. ${ }^{2}$

Table 1 shows data of the composite electrodes. While the conductivities of electrodes increase with the contents of MWCNTs, electrode densities decrease due to the low density of MWCNTs bundles. The initial efficiency is the capacity ratio of first discharge to charge at $0.1 \mathrm{C}$ rate. Amounts of additives do not affect the initial efficiency, as they are not electrochemically active for $4.3 \sim 3.0 \mathrm{~V}$ vs. $\mathrm{Li}^{2} / \mathrm{Li}^{+}$region. Fig. 3 shows charge and discharge profiles for the composite electrode with $2 \mathrm{wt} \%$ of Super $\mathrm{P}$ carbon and $3 \mathrm{wt} \%$ of MWCNTs. Compared to the reference electrode with

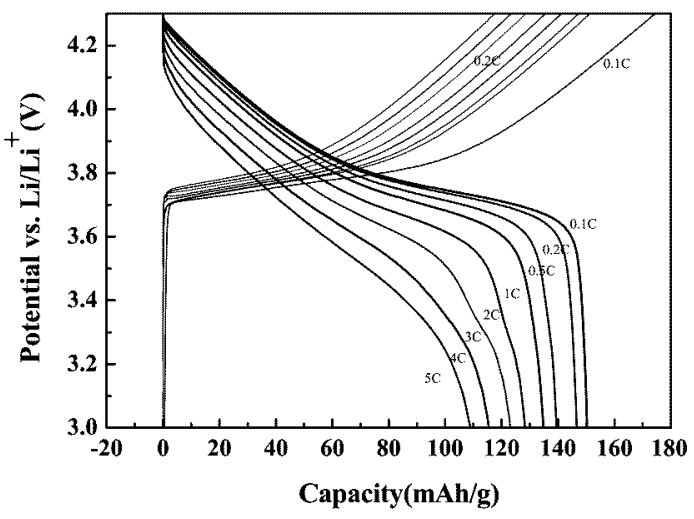

Fig. 3. Charge and discharge profiles at various $\mathrm{C}$-rates for composite cathode of $\mathrm{LiNi}_{0.3} \mathrm{Co}_{0.3} \mathrm{Mn}_{0.3} \mathrm{Al}_{0.1} \mathrm{O}_{2}$ with 2 wt $\%$ Super $P$ and 3 wt $\%$ MWCNTs.

Table 1. Characteristics of composite electrodes with various additive contents.

\begin{tabular}{cccc}
\hline Additives in $\mathrm{LiNi}_{0.3} \mathrm{Co}_{0.3} \mathrm{Mn}_{0.3} \mathrm{Al}_{0.1} \mathrm{O}_{2}$ & Electrode Density $(\mathrm{g} / \mathrm{cc})$ & Initial Efficiency $(\%)$ & Electrode Conductivity $(\mathrm{S} / \mathrm{cm})$ \\
\hline Super P 2 wt $\%$ & 2.93 & 87.7 & $0.305 \mathrm{E}-01$ \\
Super P 2 wt $\%+$ MWCNTs 1 wt $\%$ & 2.19 & 88.1 & $1.338 \mathrm{E}-01$ \\
Super P 2 wt $\%+$ MWCNTs 2 wt $\%$ & 2.00 & 88.0 & $1.520 \mathrm{E}-01$ \\
Super P 2 wt $\%+$ MWCNTs 3 wt $\%$ & 1.76 & 87.9 & $2.135 \mathrm{E}-01$ \\
\hline
\end{tabular}


한국전기화학회지, 제

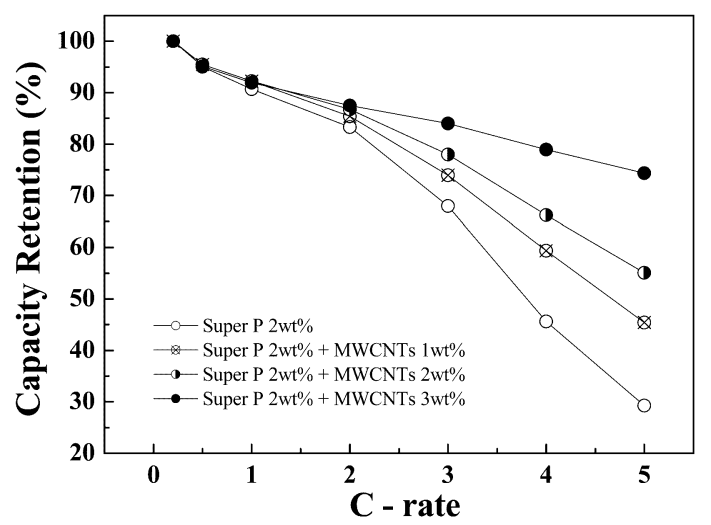

Fig. 4. Comparisons of discharge capacities for composite cathodes at various $\mathrm{C}$-rates.

$2 \mathrm{wt} \%$ of Super P carbon, the capacity at $5 \mathrm{C}$ rate was enhanced more than double. The capacity data of discharge at various C-rates were summarized in Fig. 4. Dramatic increase in high rate capabilities can be explained by two reasons. MWCNTs have higher elec- 
2. Y. H. Lee, The Korean Physical Society, 51(2), 84 (2005).

3. H. Wang and E. K. Hobbie, Langmuir, 19(8), 3091 (2003).

4. Y. Maeda, S.-I. Kimura, Y. Hirashima, M. Kanda, Y. Lian,

T. Wakahara, T. Akasaka, T. Hasegawa, H. Tokumoto, T. Shimizu, H. Kataura, Y. Miyauchi, S. Maruyama, K. Kobayashi, and S. Nagase, J. Phys. Chem. B, 108, 18395 (2004).

5. M. F. Islam, E. Rojas, D. M. Bergey, A. T. Johson, and A. G Yodh, Nano Lett., 3(2), 269 (2003).

6. L. Vaisman, G. Marom, and H. D. Wagner, Adv. Funct. Mater, 16, 357 (2006).

7. J. J. Stephenson, J. L. Hudson, S. Azad, and J. M. Tour,
Chem. Mater, 18(2), 374 (2006).

8. J. S. Sakamoto and B. Dunn, J. Electrochem. Soc, 149(1), A26 (2002).

9. K. Sheem, Y. H. Lee, and H. S. Lim, J. Power Sources, 158, 1425 (2006).

10. Q. Lin and J. N. Harb, J. Electrochem. Soc., 151(8), A11 15 (2004)

11. J.-H. Lee, G-S. Kim, Y.-M. Choi, W. I. Park, J. A. Rogers, and U. Paik, J. Power Sources, 184, 308 (2008).

12. R. S. Rubino, H. Gan, and E. S. Takeuchi, J. Electrochem. Soc., 148(9), A1029 (2001). 